\title{
Assessment of WASH \& HealthCare Waste Management in a District Hospital: A Case Study of Bangladesh
}

\author{
Yousuf TB ${ }^{1 *}$ and Mahmud $\mathrm{SG}^{2}$ \\ ${ }^{1}$ Individual Consultant for the Study, Superintending Engineer, Dhaka North City \\ Corporation, Bangladesh \\ ${ }^{2}$ National Project Officer (Wash \& Climate Change), WHO, Bangladesh
}

\section{Case Report}

Volume 1 Issue 1

Received Date: August 27, 2018

Published Date: September 19, 2018

DOI: $10.23880 /$ oajwx-16000105

*Corresponding author: Tariq Bin Yousuf, Individual Consultant for the Study, Superintending Engineer, Dhaka North City Corporation, Bangladesh, Tel: 88-01817578326; Email: tariqbinyousuf@gmail.com

\begin{abstract}
WASH and Waste management are essential part of the hospital management system with regard to healthy environment and infection control as a preventive measure from spreading diseases. Now-a-days the healthcare waste facilities are giving more emphasis on curative part of treatment rather than the preventative. A significant amount of resources are spent for patients infected with parasitic diseases caused by poor WASH and Waste Management practices. Study shows infected with diseases account for 50 percent of the in-patient bed occupancy, 33 percent of out-patient consultation adding an extra burden to hospital services that are often already overstretched. Providing access to sufficient quantities of safe water, the adequate and sound sanitation facility, proper health-care waste management system and introducing sound hygiene behavioral communication system can reduce the burden of disease transmission. The Essentials of WHO guideline of Environmental Health for infection control and management in the health-care settings and Medical Waste Management Rules 2008 of Government of Bangladesh has been taken as reference to carry out the assessment of WASH and Healthcare Waste Management situation in a District Hospital. It is found from the assessment that both the WASH and Hospital Waste Management situation are not conforming to the standards stated in WHO guideline of Environmental Health and Medical Waste Management Rules of Government of Bangladesh.
\end{abstract}

Keywords: WASH; Healthcare Waste Management; Hospital Management; Infection Control

\section{Background}

Water Supply, Sanitation \& Hygiene (WASH) and Healthcare Waste Management (HWM) are one of the essential components of hospital management from infection control and management point of view. A reliable drinking water facility and sanitation service has to be in place in the hospital both for the in-patients and out-patients. In addition, adequate water supplies facility including hand washing arrangement need to be ensured for personal hygiene practice [1,2]. This would help to control feco-oral disease, save in-hospital stay and outpatient consultation. Essential standards defined by WHO 
recommended that drinking water should meet national standards and follow WHO guidelines for drinking water quality [1]. Water for hospital use should be safe and of high quality. Sufficient water is available for use at all times. It is estimated that 40 to 60 liters of water is required for in-patients per day in hospital. This quantity can go up to above 100 liters per patient per day when surgical procedures are performed. Water should also be secured to flush toilets and for washing and hygiene purpose. Hand wash facilities with soap and alcohol based hand rub should be ensured for controlling feco-oral disease transmission.

A significant amount of medical wastes are usually generated every day from each of the health-care facilities (HCFs). The wastes are found over flowing of the bins, spread all over the premises of the health care facilities because of the absence of the dedicated waste management system which includes segregation process, collection method and disposal system. The health-care waste management rules 2008 has given directives for the proper management of healthcare wastes. The Directorate General of Hospital Services (DGHS) has also provided training, equipment and logistics to the hospitals for safe management of such wastes. But it is poorly practiced in many hospitals and health care facilities. Color coding for segregation and collection is not properly followed in most cases. In many cases it is observed that the general waste and the infectious waste are mixed which has been increasing risk of spreading the diseases among the service seekers (patents and attendant) and the providers (hospital staffs and workers) as well as the waste handlers. For example the sharps wastes, although produced in small quantities, are highly infectious, contaminated needles and syringes represent a particular threat because they are sometimes scavenged and reused. This unregulated practice spreads the germs of dreadful diseases such as hepatitis B, HIV/AIDS etc. [3].

Healthcare associated infections contribute to morbidity and mortality and to a loss of health-sector and household resources worldwide. 5-30\% of patients develop one or more infections during a stay in hospital-a significant proportion of which could be avoided by proper management of WASH and health-care waste in the hospital [1].

Generation of waste varies on a daily basis and it depends on the number of patients admitted, number of operations performed and number of patients visit to Outpatient departments (OPD). Medical wastes are mainly categorized into non-hazardous and hazardous wastes. The non-hazardous waste included kitchen waste etc. which is not required any special measure by the healthcare authority and is delivered to the municipality for management and disposal. This type of waste is generated in the patients' ward areas, out-patientdepartment (OPD), kitchens, offices, etc. The hazardous waste includes pathological, infectious, sharps and chemical wastes and are normally produced in labor wards, operation theatres, laboratories etc. [4]. The details are presented in the following schematic Figure 1.

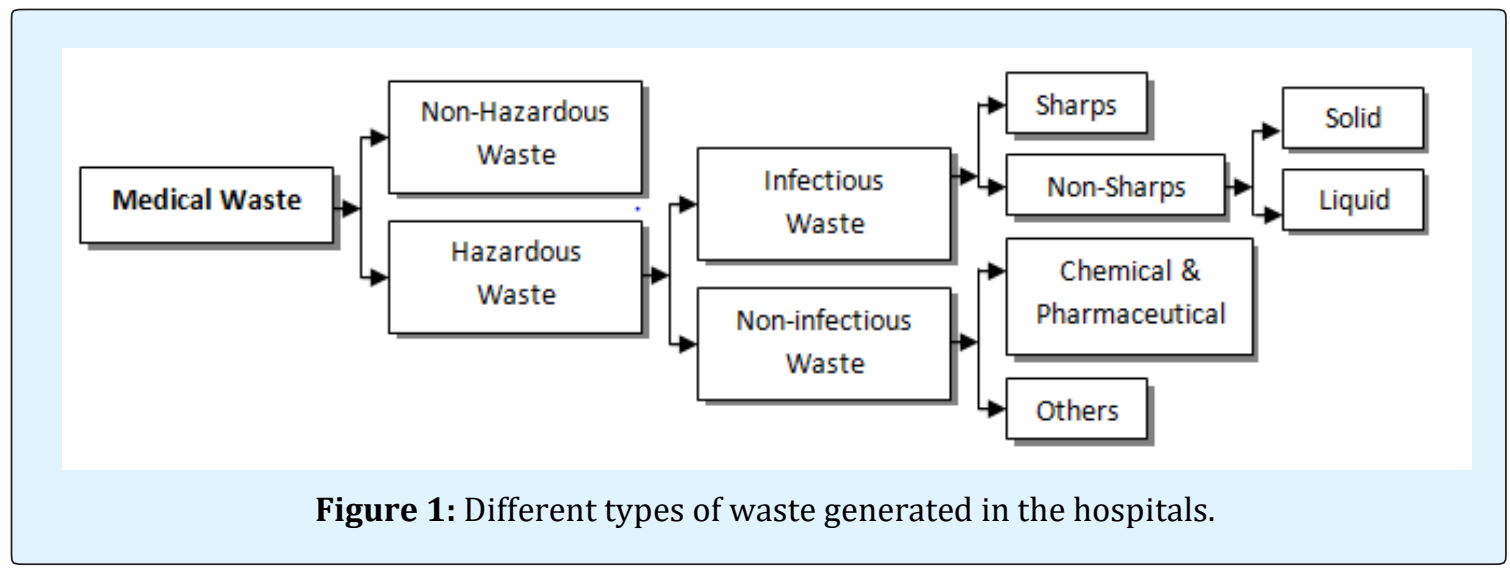

\section{Purpose of the Study}

This study seeks to help the HCF management in identifying the gaps and find out improved measures for a safe, effective, economic and appropriate environment friendly and sustainable WASH \& Healthcare waste management in the health-care facility. The study also intends to help in improving the occupational health 


\section{Open Access Journal of Waste Management \& Xenobiotics}

conditions for health care staff and caretakers through reducing the risk of people (patients, attendants, visitors, general public, scavengers etc., and animals (stray dogs, cattle etc.).

\section{Objectives of the Study}

The objectives of the study are to:

- To assess the environmental health scenario that includes waste management, water, sanitation and hygiene in terms of the service availability and readiness in the hospital

- To assess the occupational health and safety status of the related hospital staff and patients and caregivers

- To identify the gaps of the environmental health in particular the HCWM and explore best possible solution to reduce the risk of health care acquired infection.

\section{Methodology of the Diagnostic Assessment}

The study mainly followed a qualitative approach. The study emphasized capturing the relevant information from the hospital by following different methods. The primary data were collected by visiting existing facilities of the hospital. A checklist was prepared based on WHO guideline of "Essential Environmental Health Standards in Health care facilities" and "Medical Waste Management Rules 2008" of Government of Bangladesh for capturing data of the existing WASH and waste management facilities and practices and for designing future plans $[1,5]$. The study was conducted by the following data gathering process:

- A rapid assessment had been carried out using WHO's guideline on Essential Environmental Health Standards in Health care

- Visual observation was done to understand the existing situation

- Check list was used for the collection of data during the assessment period

- Meeting was conducted to analyze the occupational health and safety among the staffs

- Waste pathway (generation-storage-collectiondisposal) study was done to know the existing management system

\section{Present Situation of Health-care Service in the Hospital}

\section{General}

Cox's Bazar District Sadar Hospital is a 250-bed hospital. The number of inpatient at any point of time varied from 300 to 400 . It is indicated that a considerable number of patients have no other choice but to lie on the floor. The UNHCR has provided 100 beds in addition to the official 250 beds of the hospital which are placed on the floors. The number of outpatient varied from 800 to 1000 per day while 150 to 200 patients receive emergency services per day. The hospital was headed by a Superintendent and the human resource consisting of 39 doctors, 64 nurses, 9 medical technicians, 45 class III \& Class IV employees (Sweepers, Ward boys and Ayas) and 5 people in administration. Superintendent, Resident Medical Officer (RMO) and Ward Masters were responsible for the cleanliness and the health-care waste management of the hospital. There were 42 cleaners ( 4 from hospital, 8 from Municipality and 30 Rohingas provided by UNHCR) in the hospital.

\section{Safe Water}

The main source of water is the deep-tube well provided by UNHCR. The water is pumped into an overhead reservoir and distributed in various location of the Cox's Bazar Sadar hospital through piped reticulation. There is a water purifier in the Nursing hostel from where the hospital employees collect drinking water. Since the patients do not rely on tap water they collect drinking water from the water point in the pump house or from the nearby mosque in bottles or water pots. The tap water is not used for drinking purpose by anybody but used for hand washing, toilet flushing and medical activities only. To keep the bibcock serviceable is a challenge because it breaks or stolen by the outsiders very frequently. During the field visit, it was found that most of the taps in the washing basins were missing and the washing basins themselves were broken. The hospital authority seems to believe that ground water is safe therefore they never thought of carrying out microbiological test. In the Operation Theaters (OTs) and pathological laboratory, the same water is used. However, there was no shortage of water supply except during power failure.

\section{Sanitation}

The overall sanitation situation in the hospital is very grave. There are 2 toilets, 3 urinals and 2 bathrooms for excreta disposal, urination and bathing in each ward. The hand washing basins in some wards are either broken or 
with bib-cocks missing. Soaps are not provided for hand washing because of the fear of being stolen. Usually the patients bring soap of their own to meet their need. There is commode facility in the cabin which is comparatively clean and well fitted. . The sweepers clean the toilets of the wards twice a day. Some toilets are reserved for doctors and the staffs. The male and female wards are separated. There are separate toilets for male and female in the outpatients department. Hexisols, soaps are provided for hand washing of the doctors and nurses sufficiently from the store. Harpic, bleaching powder and finale is also supplied for cleaning the toilets. The waste water disposal system is covered and cleaned at regular interval. The septic tank is emptied when it is filled.

\section{Waste}

Healthcare wastes are highly infectious and hazardous especially to human health because those carry the germs of dreadful diseases like hepatitis B and C, HIV/AIDS etc. Healthcare waste need to be segregated, collected, transported, treated and disposed of safely. Color code with proper labeling is essential for the separate collection and disposal. In Cox's Bazar Sadar Hospital, such initiative was commenced in five years ago with the support of Directorate General of Hospital Services (DGHS). The doctors, nurses, medical staffs including other relevant persons were provided training and for waste disposal color coded bins were introduced and supplied. Three types of bins namely Black, Yellow and Red color with proper labeling were provided. The Black bins were provided for general waste, the Yellow bins were for infectious waste and the Red bins were for sharp waste. The bins were found in use but the color coding system was not properly followed for different types waste. The bins were not properly located and used according to the signs and information. The cleaning of the bins was not properly done and was stored in an open place in the corridor. The workers were not taken any protective measure during the waste handling and cleaning operation. The disposal point was a covered dustbin with a ramp and not protected from the scavengers or the stray animals. Municipality truck comes daily for waste collection from the dustbin. Hospital authority paid money to the truck driver for ensuring daily collection. The wastes were transported openly and dumped in the disposal ground with other wastes.

\section{Type and Amount of Waste Generated}

A study was carried out by WHO and DGHS in 2012 on waste generation and composition in the Health Care Centers of Bangladesh including Cox's Bazar Sadar General Hospital. According to the study, average total waste generation per day was $485.5 \mathrm{~kg}$ of which general waste $249.6 \mathrm{~kg}(51.4 \%)$, sharp $12.4 \mathrm{~kg}$ (2.55\%), liquid waste $107.2 \mathrm{~kg}(22.08 \%)$, recyclable $40.7 \mathrm{~kg}(8.38 \%)$ and infectious $75.6 \mathrm{~kg}(15.57 \%)$. Average waste generation per day per bed was $1.94 \mathrm{~kg}$. During the study, it was difficult to estimate the different types of waste without separating as all the wastes were being mixed into same container without segregation except the pathological laboratory, blood transfusion centre and operation theatres.

\section{Status of Waste Segregation Practice}

According to the Medical Waste Management Handling Rules 2008, the hospital has to design the segregation system with non-infectious general waste to put in Black, infectious waste in Yellow and Sharp waste in Red color coded bins. Initiative was undertaken by a project of DGHS for waste segregation practice in the hospital. Doctors and Staffs were provided training on waste segregation practice and three types of bins were supplied with proper labeling. However, after the project period, the segregation practice was stopped due to lack of waste monitoring system. Enough containers were provided however, in practice proper color code was not followed. Bins were not placed in proper location and proper labeling was not found.

\section{Collection and Transportation of Waste}

Wastes were collected and transported twice a day on a shift basis. Some of the containers during the collection were found empty and some were found overflowing. It indicated that the size of containers used for waste collection or the frequency of empting did not match the amount and type of waste generated in a day. The trolleys were not used for transporting the container. The containers were transported manually as found during the field visit. The wastes were collected when the patient flow in the hospital was high and transported through the patients' walking route which was a risky events for the patients and the visitors as observed.

\section{General Cleanliness}

Cleanliness is one of the basic measures for infection prevention and control in the health-care environment. In general, the hospital appeared clean and tidy. It was found during the visit that the outpatient, inpatients and waiting space of the hospital was crowded with patients and their attendants. Although the floors were found apparently clean but the bins were overflowing with wastes. Littering is also found a big problem in the hospital. Although bins were placed for waste collection, people through various stuffs and other waste materials indiscriminately. Spitting 
with the coughs and sneezes were found in and around the corners where the bins are placed. A cleaning and mopping system existed in the hospital. Dry sweeping is done in offices and lounges twice a day followed by a wet mopping. The specialized rooms such as operation theatres, delivery rooms, pathologies were cleaned by detergents or disinfectants. The toilets were cleaned by disinfectant (bleaching powder and Harpic) daily and when required. The hospital out-premises were swept daily and drains were cleaned twice in a week.

\section{Health Protection of Staff}

Hospital waste carries germs. Staffs were found at risk because of their inadequate personal protective equipment (PPE) during waste collection and transportation. Staffs did not use masks and gloves. The awareness among the staffs was found absent regarding the waste handling. No strict monitoring on proper use of personal protective equipment such as protective clothing, gloves and masks was found among the different category of staff.

\section{Gaps Identified in WASH and Waste Management in Hospital}

\section{Water Supply}

In the healthcare facilities, water supply should be reliable. In hospital premises, water for drinking, cooking, personal hygiene, medical activities, cleaning should be safe, sufficient water should be available at all times and sufficient water points and water use facilities should be available. The standard measures and existing situation of water supply with identified gaps is presented in Table 1 [1].

\begin{tabular}{|c|c|c|}
\hline Standard Measure & Existing Situation & Gaps \\
\hline $\begin{array}{l}\text { A reliable drinking water point is } \\
\text { accessible for staff, patients and } \\
\text { patient attendants at all times. } \\
\text { Drinking water points should be } \\
\text { clearly marked. Reliable water point } \\
\text { with soap or suitable alternative is } \\
\text { available at all critical points within } \\
\text { the HCS (operation theatres, wards, } \\
\text { consultation chamber, dressing } \\
\text { stations etc.) and in the service areas } \\
\text { (sterilization laboratory, toilets etc.). } \\
\text { There need to be at least two hand } \\
\text { washing basins in wards with more } \\
\text { than 20 beds Drinking water } \\
\text { supplied should meet national } \\
\text { standards and follow WHO guideline } \\
\text { for drinking water quality. Inpatient } \\
\text { settings need to have sufficient } \\
\text { showers (at least one shower for } 40 \\
\text { users and separate showers for both } \\
\text { sexes for privacy and safety). }\end{array}$ & $\begin{array}{l}\text { There is no reliable drinking water facility } \\
\text { found in the hospital accessible for staff, } \\
\text { patients and their attendants. The deep } \\
\text { tube well water is assumed as safe drinking } \\
\text { water source. Water is available at all times } \\
\text { except during long time power failure. The } \\
\text { operation theatres, consultation chambers, } \\
\text { dressing stations, pathological laboratory } \\
\text { and blood transfusion centre are equipped } \\
\text { with hand wash basin with soap or alcohol } \\
\text { based rubbing. The wards are mainly } 20 \\
\text { bedded but } 10 \text { extra beds are also provided } \\
\text { on the floor. There are two hand washing } \\
\text { basins found near the toilets in the wards, } \\
\text { however in most cases the taps of the } \\
\text { washing basins are missing. There are two } \\
\text { shower facilities in the wards which are } \\
\text { sufficient for the patients admitted in the } \\
\text { wards. The male and female patients has } \\
\text { separate wards so in terms of privacy and } \\
\text { safety, there is apparently no problem. }\end{array}$ & $\begin{array}{l}\text { Reliable drinking water } \\
\text { facilities with clearly marked } \\
\text { as safe drinking water is } \\
\text { absent. Piped water supply in } \\
\text { the hospital is unreliable for } \\
\text { drinking. No micro-biological } \\
\text { test has been carried out of the } \\
\text { supplied water so far. Public } \\
\text { Works Department (PWD) is } \\
\text { mainly responsible for the } \\
\text { maintenance of the building } \\
\text { and its plumbing system. But } \\
\text { they hardly take care or } \\
\text { response to this issue. Hand } \\
\text { washing basins or the fittings } \\
\text { in the wards are mostly } \\
\text { missing and inconvenient for } \\
\text { the users. }\end{array}$ \\
\hline
\end{tabular}

Table 1: Comparison for standard measures and existing situation of water supply.

\section{Sanitation}

Adequate, accessible and appropriate toilets for patients, staff \& visitors need to be ensured for ensuring proper sanitation and hygiene facilities. The standard measures and existing situation of sanitation is presented in Table 2 [1]. 


\begin{tabular}{|c|c|c|}
\hline Standard Measure & Existing Situation & Gaps \\
\hline $\begin{array}{l}\text { Sufficient toilets are available in HCFs (one } \\
\text { toilet per } 20 \text { users for inpatient settings } \\
\text { and four toilets for outpatients: staff- } 1 \text {, } \\
\text { male patient- } 1 \text {, female patient- } 1 \text { and } \\
\text { children-1). Toilets are easily accessible } \\
\text { for all users (no more than } 30 \mathrm{~m} \text { from all } \\
\text { users), lockable by the users and lighting } \\
\text { facilities at night. Toilets provide privacy } \\
\text { and security (male and female specified). } \\
\text { Clearly sign posted to help users for } \\
\text { finding those. Toilets have convenient } \\
\text { hand washing facilities close by. A routine } \\
\text { cleaning and maintenance is in operation } \\
\text { that ensures clean and functional toilets } \\
\text { are available at all times. Toilets are } \\
\text { cleaned whenever those become dirty and } \\
\text { at least twice per day (with brush and } \\
\text { disinfectant). Toilets are connected to a } \\
\text { sewer system or septic tank and drainage } \\
\text { system. Toilets are equipped to make easy } \\
\text { to use by people with physical handicaps, } \\
\text { heavily pregnant women, elderly/sick } \\
\text { people. Adequate drainage of waste water } \\
\text { with cover to avoid the risks of disease } \\
\text { vector breeding. }\end{array}$ & $\begin{array}{l}\text { There are two toilets in each ward for } \\
20 \text { patients in bed and } 10 \text { patients } \\
\text { bedded on the floor. The toilets were } \\
\text { not hygienic in terms of keeping them } \\
\text { clean through proper flushing. The } \\
\text { cleaners cleaned the toilets twice in a } \\
\text { day but the users did not maintain the } \\
\text { cleanliness. The taps of the wash basin } \\
\text { in the toilets are missing. For the } \\
\text { outpatient unit, there are separate } \\
\text { toilets for hospital staff, male and } \\
\text { female. No separate toilet facility exists } \\
\text { for the children. The patients managed } \\
\text { their own soap for hand washing. } \\
\text { There was also a public toilet in the } \\
\text { hospital premises leased out by the } \\
\text { municipality. Lock and lighting } \\
\text { facilities were not sufficient. There was } \\
\text { support facility for the elderly or sick } \\
\text { patients. Some toilet fittings had been } \\
\text { broken and repair work was not done } \\
\text { by PWD for a long time. Septic tanks } \\
\text { usually emptying when they were } \\
\text { overflowing. }\end{array}$ & $\begin{array}{l}\text { Sanitation situation in the } \\
\text { hospital is dismal from } \\
\text { hygienic point of view. There } \\
\text { is a cleaning program for the } \\
\text { toilets from the hospital } \\
\text { authority but the users often } \\
\text { make them dirty. It is tried by } \\
\text { the hospital authority to keep } \\
\text { hand wash soap but difficult } \\
\text { for them to maintain because } \\
\text { of missing. The taps or other } \\
\text { fittings are either broken or } \\
\text { stolen. Locking and lighting } \\
\text { facilities are insufficient and } \\
\text { not regularly addressed. } \\
\text { There is no regular } \\
\text { monitoring of cleaning } \\
\text { schedule and no initiative has } \\
\text { been taken from the hospital } \\
\text { authority for remedial } \\
\text { measure or improving the } \\
\text { situation. }\end{array}$ \\
\hline
\end{tabular}

Table 2: Comparison for standard measures and existing situation sanitation and identified gaps.

\section{Cleaning and Hygiene Practice}

Floors and the surfaces in the healthcare facility are to be kept clean. Routine programmed cleaning; sweeping and wet mopping is to be ensured. The standard measures and existing situation of cleaning and hygiene practice is presented in Table 3 [1].

\begin{tabular}{|c|c|c|}
\hline & on & Gaps \\
\hline $\begin{array}{l}\text { Sweeping daily (office and non-patient } \\
\text { areas), wet mopping daily (waiting areas, } \\
\text { consultation rooms, wards, pharmacy), } \\
\text { cleaning with detergent/disinfectant (OT, } \\
\text { delivery rooms, ICU, casualty departments, } \\
\text { laboratory, kitchen etc.). Any area } \\
\text { contaminated with blood or body fluids are } \\
\text { cleaned and disinfected immediately, } \\
\text { beds/pillows/linens are cleaned between } \\
\text { discharged and admitted patients and } \\
\text { whenever soiled with body fluid, beds are } \\
\text { wiped with disinfectant solution following } \\
\text { each hospitalization. Staff are trained and } \\
\text { managed in a way that encourages } \\
\text { consistent compliance with infection } \\
\text { control procedures. Patients and attendants } \\
\text { are informed about essential behaviors } \\
\text { necessary for limiting disease transmission }\end{array}$ & $\begin{array}{l}\text { Sweeping of the premises and the } \\
\text { floors are done regularly. There was } \\
\text { a cleaning schedule of the sweepers. } \\
\text { The waiting areas, consultation } \\
\text { rooms, wards were mopped twice in } \\
\text { a day. The OT, delivery rooms, ICU, } \\
\text { casualty department, laboratory } \\
\text { rooms were cleaned by disinfectant. } \\
\text { The toilets inside the OT and ICU } \\
\text { were cleaned twice daily by using } \\
\text { detergent. Hand washing facilities } \\
\text { were not sufficient. It was difficult for } \\
\text { the hospital authority to keep soap } \\
\text { for hand washing in the hand } \\
\text { washing basins. There was no } \\
\text { committee existed to monitor the } \\
\text { cleaning activities. The staffs were } \\
\text { not trained and also patients and }\end{array}$ & $\begin{array}{l}\text { The supervision and } \\
\text { monitoring of the cleaning } \\
\text { service from the hospital } \\
\text { authority is absent. Ward } \\
\text { master is responsible on } \\
\text { adhoc-basis. There is no } \\
\text { committee for reporting or } \\
\text { addressing the overall } \\
\text { cleanliness of the hospital. } \\
\text { There is no mechanism of } \\
\text { training or rewarding the staff } \\
\text { for encouragement. Patients or } \\
\text { visitors are not informed about } \\
\text { their responsibilities for } \\
\text { cleanliness during their stay in } \\
\text { the hospital. No visual advice } \\
\text { or instructions are seen for } \\
\text { awareness and practice on }\end{array}$ \\
\hline
\end{tabular}

Yousuf TB and Mahmud SG. Assessment of WASH \& HealthCare Waste Management in a District Hospital: A Case Study of Bangladesh. J Waste Manage Xenobio 2018, 1(1): 000105. 


\section{Open Access Journal of Waste Management \& Xenobiotics}

\begin{tabular}{|c|c|c|}
\hline $\begin{array}{l}\text { in HCS. Posters and other visual } \\
\text { information should be used to promote } \\
\text { disease control among patients and } \\
\text { attendants. }\end{array}$ & $\begin{array}{l}\text { visitors were not consulted about the } \\
\text { hygiene for infection control. Posters } \\
\text { and promotional messages are } \\
\text { absent. }\end{array}$ & $\begin{array}{l}\text { cleanliness and infection } \\
\text { control. }\end{array}$ \\
\hline
\end{tabular}

Table 3: Comparison of standard measures and existing situation of cleaning and hygiene practice and identified gaps.

\section{Waste Collection and Disposal}

Management of health-care waste is an integral part of hospital hygiene and infection control. Health-care waste is considered as a reservoir of pathogenic microorganisms, which can cause contamination and give rise to infection. If waste is inadequately managed, these micro-organisms may be transmitted by direct contact, in the air or by a variety of vectors. Infectious waste contributes to the risk of noso-comial infections, putting the health of hospital personnel and patients, at risk. The standard measures and existing situation of healthcare waste management is presented in Table 4 [1].

\begin{tabular}{|c|c|c|}
\hline Standard Measure & Existing Situation & Gaps \\
\hline $\begin{array}{l}\text { Health-care waste } \\
\text { has to be segregated, } \\
\text { collected, } \\
\text { transported, treated } \\
\text { and disposed of } \\
\text { safely. Health-care } \\
\text { waste is segregated } \\
\text { at the point of } \\
\text { generation according } \\
\text { to its type \& } \\
\text { categories: sharps, } \\
\text { non-sharps infectious } \\
\text { waste, non-sharps } \\
\text { non-infectious waste. } \\
\text { Color-coded waste } \\
\text { containers bror or } \\
\text { containers bearing } \\
\text { clearly understood } \\
\text { signs and symbols } \\
\text { are provided at } \\
\text { convenient locations. } \\
\text { They are collected } \\
\text { from all health-care } \\
\text { services and stored } \\
\text { safely before } \\
\text { treatment and/or } \\
\text { disposal. } \text { Each } \\
\text { category of waste is } \\
\text { treated and disposed } \\
\text { of according to the } \\
\text { safest feasible } \\
\text { method. }\end{array}$ & $\begin{array}{l}\text { Three type bins following the color code were provided in } \\
\text { the hospital by the DGHS. But segregation and separate } \\
\text { collection and disposal are completely absent. All types of } \\
\text { wastes are put together. Cleaners have no awareness and } \\
\text { training on handling the wastes. Training was provided } \\
\text { three years ago regarding the use of bins. But not continued } \\
\text { or practice was monitored. The cleaners were found not } \\
\text { wearing protective gears and reluctant of associated risks. } \\
\text { The bins were labeled with text but the pictorial } \\
\text { representation was absent. The labeling and position of the } \\
\text { bins were mismatched. The size of the black bin was very } \\
\text { small. Most of the bins were full and overflowing. The lids } \\
\text { of the bins were lost. The bins were taken to the disposal } \\
\text { point for unloading and washed openly by water without } \\
\text { using disinfectant. Bins placed in the wards, waiting spaces } \\
\text { were found dirty. Bins were not properly cleaned and } \\
\text { disinfected. The cleaning of bins was done in open place. } \\
\text { The bins for infectious wastes need to be disinfected before } \\
\text { placement which was completely missing. Segregation of } \\
\text { medical wastes was not conducted properly. Color code } \\
\text { was not followed during source segregation except the } \\
\text { pathological lab. In the wards, mixed waste including } \\
\text { syringe with needle was found in the bins. Trolleys were } \\
\text { not used for internal transportation of the bins. Needle } \\
\text { cutters were not used in all medical unitsThe municipality } \\
\text { truck comes everyday for collection. There was no } \\
\text { treatment system of any type of waste and systematic } \\
\text { recycling system was absent. All types of waste were } \\
\text { disposed of in a dustbin from where the municipality truck } \\
\text { collects waste daily. The papers, cartons, plastic etc. were } \\
\text { collected by the cleaners or ward boys of the hospital, } \\
\text { stored in a room and sold to the scrap dealers. The } \\
\text { unscrupulous people collect the saline, blood bags and } \\
\text { syringe from the dustbins which might have chance to } \\
\text { resale and reuse in the hospital or any other healthcare } \\
\text { establishment. }\end{array}$ & $\begin{array}{l}\text { Waste segregation, separate } \\
\text { collection and disposal are } \\
\text { completely absent. Color code is } \\
\text { not properly followed either in } \\
\text { bin placement or in practice. The } \\
\text { instructions or labeling are } \\
\text { wrongly pasted on the wall. } \\
\text { Cleaners are not aware of the } \\
\text { danger with handling healthcare } \\
\text { waste. Trolleys for internal } \\
\text { transportation, internal storage } \\
\text { of bins, cleaning of bins all are } \\
\text { very improperly managed. } \\
\text { Needle cutters are not used and } \\
\text { syringes with needles are found } \\
\text { in the bins or in the disposal } \\
\text { points giving scope to the } \\
\text { unscrupulous scavengers to } \\
\text { collect and resale. There is no } \\
\text { system of separate treatment of } \\
\text { waste. Recovery of recyclable } \\
\text { materials is done by both the } \\
\text { hospital staff and the scavengers. } \\
\text { Scavengers spread the waste in } \\
\text { the disposal point and collect the } \\
\text { soiled paper, plastic materials } \\
\text { from the mixed waste. There is } \\
\text { no record of waste generation } \\
\text { and disposal. Municipal truck } \\
\text { collects waste daily from the } \\
\text { dustbin located in the hospital } \\
\text { premises and dumped with } \\
\text { general wastes in the disposal } \\
\text { ground. }\end{array}$ \\
\hline
\end{tabular}

Table 4: Comparison of standard measures and existing situation of health-care waste management and indentified gaps. 


\section{Open Access Journal of Waste Management \& Xenobiotics}

\section{Recommendations}

WASH and Waste management are essential part of the hospital management system with regard to cleanliness and infection prevention and control as a measure of spreading diseases. The assessment of the existing situation has been done based on the essential environmental health standard in healthcare facilities and the gaps are identified for improvement. It is found from the assessment that the hospital has given too much emphasis on clinical intervention for curing diseases and very little on its prevention. Hospital needs to set an example of being a clean and hygienic place in the community. It needs to demonstrate how to maintain cleanliness of hospital by ensuring proper water supply, sanitation and waste management. The overall guiding principles for the improvement of the hospital sanitary environment are as follows:

- For safe drinking water supply, at least 10 (ten) water points with filter (Outpatient Departments-2, Male ward-1, Female ward-1 in ( $1^{\text {st }}$ floor $\& 2^{\text {nd }}$ floor $)$, doctors canteen-1, general canteen-1, Neo-natal unit-1, superintendent room-1) need to be installed and clearly marked as drinking water point.

- Existing toilets need to be repaired and maintained with hand washing facilities.

- A health education desk should be developed for raising awareness to patients and visitors to use the hospital's waste bins of different category and color coding system; explain them the implications of the dangers of using certain infected recycled medical items. Information by posters and leaflets on hygiene promotion and practice should be displayed in the hospital premises to educate the people.

- Regular sweeping, wet mopping and cleaning service should be closely supervised and monitored. For this a written reporting system can be developed and used.

- Segregation following the color coding, separate collection, treatment and safe disposal of healthcare waste should be ensured in the hospital.
- A workable Infection Prevention and Control Committee including cleanliness and waste management should be formed for regular meeting and inspection of the hospital cleanliness and waste management facilities .

- Wastes from the pathological laboratory and isolation wards should be disinfected by autoclave before disposal

- Recycling practice of medical wastes may cause the risks of infection, so measures should be taken to prevent the recycling of hazardous items or otherwise reduce the risk associated with the items by disinfected them by chlorination before they are recycled.

- Reward system with clean ward contest should be conducted for encouraging the concern staffs of the hospital. It will motivate the staff to keep their working place such as wards clean.

\section{References}

1. John A, Jamie B, Yves C (2008) Essential Environmental Health standards in Health Care. World Health Organization.

2. Pruss A, Giroult E, Rushbrook P (1999) 'Safe Management of wastes from health-care activities' World Health Organization, Geneva, pp: 1-14.

3. Rahman A, Saidur KM (2000) Situation Assessment and analysis of hospital waste management. Directorate General of Health Services (DGHS), Dhaka.

4. Adrian C, Jurg C (1999) How are we managing our healthcare wastes? Swiss Centre for Development Cooperation in Technology \& Management, SKAT

5. GOB (2008) Medical Waste (Management and Processing) Rule 2008, Ministry of Environment \& Forest, People's Republic of Bangladesh. 